\title{
Engaging the Extreme Poor People with Private Sector for Livelihood Resilience
}

\author{
M. Mizanur Rahman* \\ NOHA Mundus Scholar at the Uppsala University, Sweden and Post Graduate Fellow, Stephen Zuellig Graduate School of \\ Development Management, Asian Institute of Management, Philippines \\ *Corresponding author: mithunmds07@gmail.com
}

Received March 19, 2014; Revised April 15, 2014; Accepted September 22, 2014

\begin{abstract}
Bangladesh made significant improvement in reducing poverty since its independence in 1971 however, diverse developmental challenges remain. The role of public, private and non-governmental actors in poverty reduction has been widely recognized in the literature. Numerous private sector initiatives are proliferating within NGOs' project portfolios as an opportunity for an innovative approach to poverty reduction. Despite this progress, studies have shown that the degree to which households above the poverty remain highly vulnerable and could slide back into poverty when faced with an economic shock such as loss of working opportunity, food price inflation, illness, natural disasters and other crises. Therefore, beyond attention to poverty alleviation, addressing households' resilience is crucial to make this progress sustainable. Using a case study approach, this study investigates how a private sector intervention undertaken by NGOs effectively helps the extreme poor households build their livelihood resilience. The case study considered in this research is based on the Social and Economic Transformation of the Ultra-poor (SETU) project of CARE Bangladesh regarding its collaboration with Classical Handmade Products-BD (CHP-BD), an export oriented rug-manufacturing company. Under this collaboration in SETU (phase-1), nearly 270 females from extremely poor households (i.e. SETU project beneficiaries) engaged in rug production of CHP-BD who could create resilient livelihoods and moved them from lower productivity housemaid works to higher productivity rug factory working though they had to face income shock due to a sudden closure of the factories for a couple of months. The study analyses the coping strategies adopted by the workers during the closure. It explores the ways in which workers learnt from this event and changed their behaviour in terms of savings, income diversification and strengthening social connections. The author also analyses how this change in behaviour helps them build livelihood resilience towards potential shocks.
\end{abstract}

Keywords: resilience, livelihood, private sector, poverty, rug factory, income diversification, productive asset

Cite This Article: M. Mizanur Rahman, "Engaging the Extreme Poor People with Private Sector for Livelihood Resilience.” American Journal of Rural Development, vol. 2, no. 4 (2014): 59-67. doi: 10.12691/ajrd2-4-1.

\section{Introduction}

According to the United Nations Development Programme (UNDP), Bangladesh has made remarkable progress in the areas of poverty reduction when the Household Income and Expenditure Survey [1] of 2010 data show that the incidence of poverty is declining at a rate of 2.47 percent per year since 1991-92 in Bangladesh [2]. But this progress was made possible due to the stable economic growth accompanied by gradual transformation of the sectoral composition of the GDP culminating in greater share of manufacturing and services sectors and declining share of agriculture. Some of the literature on the agricultural sector of Bangladesh questions the role of agriculture in reducing poverty. Rahman [3] argues that agriculture is rarely commercially viable for many poor farmers and if we really want to make agriculture financially viable for the poor, it is more important to give them relief from the pressure of the rising cost of inputs first. Therefore poverty alleviation through agriculturebased intervention is limited especially since the country experiences a reduction of agricultural land base and reaches the limits of its cropping capacities. Crop agriculture in Bangladesh is subdued by multiple challenges every year when the major ones include loss of arable land, population growth, climate changes, inadequate management practices (fertilizer, water, and pests and diseases), lack of quality seeds, and inadequate credit support to farmers, unfair price of produces, and insufficient investment in research. This situation leads people think upon the growth with limited dependence on agriculture. Evidences from developing countries point towards the growing importance of non-farm activities in the income-generating portfolio of rural households $[4,5]$ and that is why the potential role of private sector in poverty alleviation is thought to be crucial.

The industrialization and privatization process in Bangladesh evolved gradually and expanded particularly fast since 1993 [6]. According to a study by Hossain [7], the relative importance of agriculture as a source of 
employment for the rural workforce has decreased significantly over the past two decades. From the last two and half decades, people have started shifting to the garment industries finding it a relatively better source of employment and Bangladesh's garment industry provides employment to more than 3.6 million workers [8], which accounts for a notable change in the composition of the labour market in Bangladesh.

Private sector has been considered as engine of growth, it has been imperative to make the rural people get the benefit of privatization [9]. There is growing realization that in order to make development sustainable, the private sector must be brought in the poverty-reduction dialogue.

Bangladesh has for many years been awash with programmes and projects designed to eliminate poverty. Besides, public sector initiatives were reinforced by donor initiatives to channel resources to the NGOs which were involved in implementing a variety of schemes targeted at the poorer households [10]. The effectiveness of those initiatives in terms of sustainable graduation out of poverty and the increased resilience of those graduated households remains to be proven.

For the sustainable graduation of the extreme poor households, CARE Bangladesh has been implementing 'Social and Economic Transformation of the Ultra-poor' (SETU) project in Northwest part of Bangladesh since February 2009 with the purpose of empowering 40,000 extreme poor households. The project is supported by Shiree (a management agency contracted by GoB and DFID). One of the efforts of the economic empowerment strategy for SETU project is to build relationships with private sector stakeholders and service providers to expand economic activity and employment opportunities that enable the participation of the extreme poor and poor. Based on experience from SHOUHARDO Program, SETU Project previously (i.e. in phase-I) built a collaborative relationship with CHP-BD under which CHP-BD trained CARE's SETU project beneficiaries and engaged them in mat/rug making job. Seeing good result of the collaborative initiative with CHP-BD, CARE SETU management has scaled up this collaboration in SETU phase-II. However, after being involved with the rug factories (started in SETU phase-1), the workers started having a good amount of monthly earning but the factories had a sudden shock and remained closed and took six to twelve months to restart varying from factory to factory. This unpredictability of private sector in terms of operation running has questioned the livelihood resilience issue of the rug factory workers and that is why, the study aims to look into how and to what extent the workers are resilient towards shocks.

The paper presents the background, literature review, conceptual framework of the study and the methodology used. The analytical section (section 5) explores and analyses the coping strategies adopted by the workers during the closure. Then, the way in which workers learnt from this event and changed their behaviour in terms of savings, income diversification and strengthening social connections is analysed together with the ways in which these often help them build resilient livelihoods. The conclusion summarizes key findings on the basis of which recommendations are made.

\section{Literature Review}

Barrett et. al. [11] argued that poverty reduction policies generally aim to improve the asset holdings of the poor, either by endowing them with additional financial, fixed, human, natural, or social assets, by increasing the productivity of assets they already hold, or both and this is how they tend to diversify their income sources. Diversification of income is widely understood as a form of self-insurance in which people exchange some foregone expected earnings for reduced income variability achieved by selecting a portfolio of assets and activities that have low or negative correlation of incomes $[12,13]$. If the rural extreme poor people are engaged with the private sector or in the service sector, it is supposed to have some backward and forward linkages. That is why, it is expected that a stable and higher income influences the poor in investing in and/or accumulating assets to mitigate risks and increase resilience.

Some authors also noted that investment for asset can be a self-insurance strategy to minimize risks and better cope with risk of adverse shocks [14]. Based on data collected in rural Africa they found that income diversification through investment in productive asset to cope ex post is an effective strategy for the extreme poor to cope with income shocks. In rural economy, diversification of income is observed as a non-deliberate action of the households but those are accounted for a good return in times. In remote areas where physical access to markets is costly and causes (household-specific) factor and product markets failures, households diversify production patterns partly to satisfy own demand for diversity in consumption [15]. Homestead gardening, livestock rearing, land leasing are seen as common practice and are often useful for coping with economic shocks.

Studies have shown that households having more diversified income are more capable to absorb economic shocks. Reardon et al. [16] find that households' capacity to cope with the drought shocks of the mid-1980s in Burkina Faso were strongly associated with the extent of their non-farm diversification patterns. They argued that households with greater income diversification were able to buy food and weather the effects of the drought, and tended to have higher overall incomes than those who were not able to supplement their farm incomes with rural nonfarm (RNF). Again, the risk preferences and differential access to wealth is likely to contribute to greater demand for ex-ante diversification by poor people, so too are the poor more likely to diversify ex-post as a coping response to shocks [17]. That is why, after experiencing a shock, the poor people are expected to have more income diversification measures.

According to a large stand of the literature, the poor when earning a high income commonly start saving and thus try to get some livelihood resilience. Stuart [18] documents how poor households often report wanting to save more. Banerjee and Duflo [19], looking at detailed household survey data from 13 countries, find that even extremely poor households do not use all of their income to afford basic necessities rather they go for savings so that those can be utilised in creating some other income sources and meeting any emergency demand. 
With the objective of making livelihood improvement sustainable, development initiatives' effectiveness is increasingly assessed on the ability of beneficiaries to cope with and recover from stress and shocks [20]. Building resilience, defined as the "maintenance of positive adjustment under challenging conditions" [21] refers to the capacity to adapt or evolve with changing environmental conditions [22].

Rural Bangladeshi women often manage complex households and pursue multiple livelihood strategies but their labour in maintaining the households is often unrecognized and they have several constrains to be economically active like the counterparts. However, they are expected to specialize in unpaid domestic work and also there are strong cultural restrictions on their mobility in the public domain [23]. But with some NGO interventions, women have been able to get some mobility, economically activeness and social connectedness [24]. Similarly, the involvement of the extreme poor female with the rug factories is expected to have some more mobility, economically activeness and social connectedness.

Social connectedness is often helpful for livelihood resilience for the poor people. The poorest cannot construct social capital for their benefit due to their lack of 'able-bodiedness', limiting relationships with kin and wider social circles, and their inability to articulate and be influential within public spheres. Social exclusion is therefore wedded to the concept of social protection of marginalized and vulnerable groups. The SETU project categorically targeted social empowerment of the extreme poor as one of the major three results of the project. The Social Empowerment dimension of the SETU graduation model ${ }^{1}$ captures the demand for changes in social relationships that help to shape the livelihoods, experiences and opportunities. This strengthening of social relationships is expected to have a significant change in the wellbeing status of the extreme poor as well by ensuring a greater social connectedness and eradicating marginalization and exclusion. The initiatives aim to build up mutual understanding and emerge of sense of cooperation among all the people in the society.

Available literature in Bangladesh shows the positive impact of income diversification through investment in productive asset creation and social connectedness on livelihood resilience separately. The dual impact of these two processes through private sector initiative on the rural extreme poor is still under-studied.

\section{Conceptual Framework}

Based on the identified literature review, it has been understood that income diversification, savings and social connectedness play an important role in helping extreme poor household to build livelihood resilience. This study has considered these as important means of attaining livelihood resilience for the rug factory workers.

"Sustainable Livelihood" is used in this paper to refer to a source of income that can cope with and recover from stresses and shocks, maintain or enhance its capabilities

1 Please see the detail graduation model at Social and Economic Transformation of Ultra-poor (SETU) project memorandum and assets both now and in the future, while not undermining the natural resource base [25].

In this study, livelihood diversification refers to the efforts by individuals and households to find new ways to raise incomes. Livelihood diversification includes both on- and off-farm activities which are undertaken to generate income additional to that from the main household income generating activities [26]. Diversification is generally recognised as an important strategy for decreasing livelihood vulnerability, defined by Ellis [27] as follows:

"Rural livelihood diversification is defined as the process by which rural households construct an increasingly diverse portfolio of activities and assets in order to survive and to improve their standard of living."

The term 'shock' referrers to any kind of interruption to the main earning scopes or any obstacle to continue with the main means of earning. In this study, the 'shock' has been taken for mainly closure of the factories and health hazards.

Two hypothesises were made before the conduction of field work:

1. After being engaged with the private sector initiative, the increased level of income would help people invest for creating some productive assets with the aim of having some diversified income sources. They would also have some money saved formally or non-formally so that they can utilise that when necessary and thus they would reduce their vulnerability.

2. The social connectedness help the extreme poor people get access to the wider community and build some social connectedness. At the same time, the employment of the female is also helping them have some strong intra and inter familial relationships, which all are the potential means of attaining livelihood resilience. Details can be seen in Figure 1.

It is assumed that after being involved with the rug factory, the workers get some regular income and at the same time, they get access to a wider community. From the income, they are supposed to meet their regular expenditures, keep some money as savings with the formal or non-formal financial institutions and some money in hand for investing for creating some productive assets (PA). These productive assets can create more income generation that will craft more scopes for them to meet the expenditures and investment with the rest of the money. Thus, the income from their involvement with the rug factory could help them attain resilient livelihood. In the other side, their access to the wider community might increase their group solidarity and social networks, which will eventually help them have more social connectedness. Due to having these social connections, the rug workers are expected to have more cooperation from the people to cope with sudden shocks and thus it could help them attain resilient livelihood.

\section{Research Methodology}

In the SETU project, graduation is conceptualized as 'achieved' when an extreme poor person or household reaches a level of economic well-being sufficient to meet their basic needs (for nutrition, health, education and shelter) along with the levels of social and political 
inclusion necessary to sustain that improved level of wellbeing over the long-term. Towards this end, the project designed a 7 year graduation model, particularly for the bottom 10 percent of extreme poor households, to have a positive sustainable impact in their lives. The path of graduation identified through expansion of capabilities and freedoms of the extreme poor households at certain intervals.

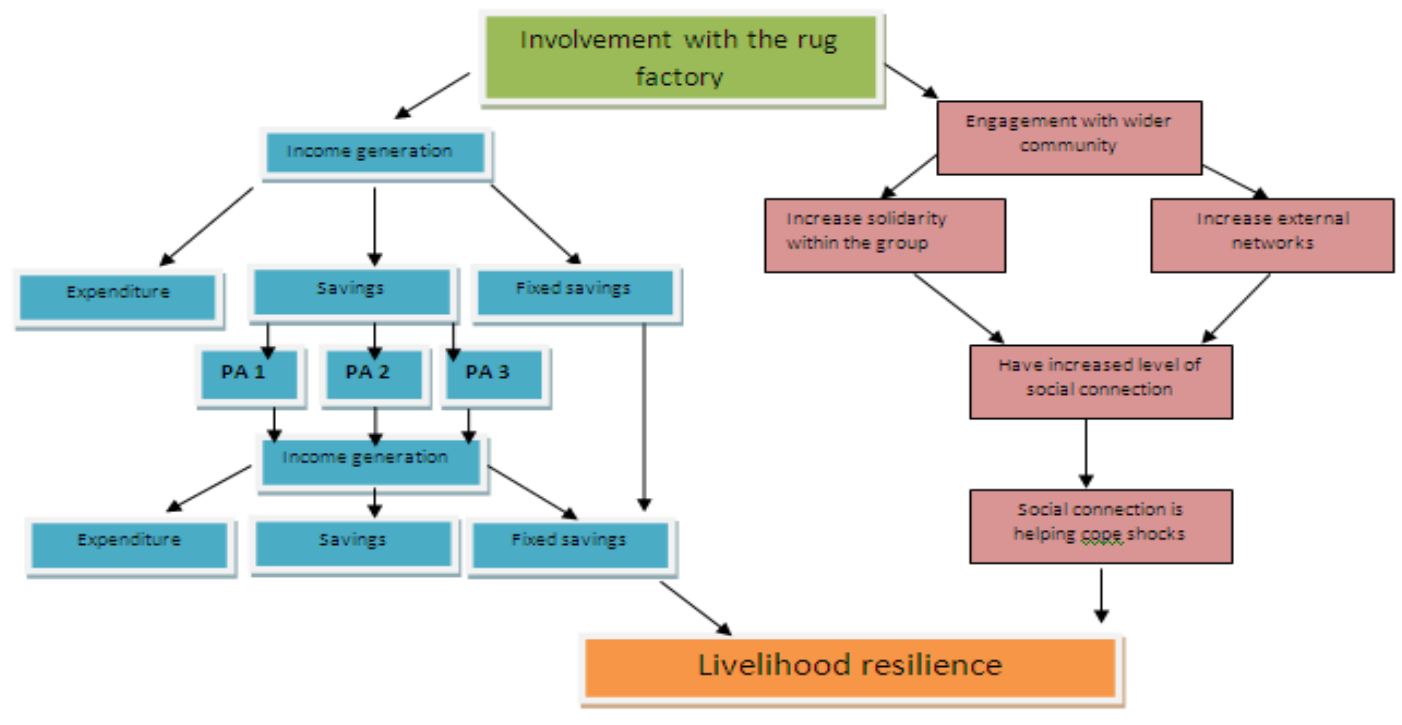

Figure 1. Livelihood resilience process of the rug factory workers

In the graduation model of the project, the three dimensions of empowerment - social, economic and political - are closely inter-related and mutually reinforcing, such that facilitating economic empowerment requires a process of enabling significant transformation in the social and political relations of power, so that gains by the extreme poor in the economic realm can be sustained. Evidence from the SHIREE ${ }^{2}$ programme shows that economic empowerment without social and political empowerment can often lead to the powerful 'taking the gain' ${ }^{3}$.

As an initiative of economic empowerment of the extreme poor, the project conducted the Participatory Poverty Analysis (PPA) where wellbeing analysis was the key part of that with the active participation of the community people. After the wellbeing analysis with this participatory approach, the project selected the bottom 10 per cent people as the project participants. Then, with the selected participants, the project conducted the skill analysis process to see what types of income generating activities were suitable for individuals. With this process, all the rug factory workers were selected and trained up for rug production and provided them with the rug production machines and the raw materials.

The study investigates to what extent does engaging extreme poor females with private rug factories contribute to build their resilience. Specifically, the study aims:

1. To identify whether the involvement/engagement of extreme poor women with the rug factories led to income diversification strategies through productive asset investments

2. To understand to what extend female factory workers are/were resilient towards income shock through their social connectedness

\footnotetext{
${ }^{2}$ Stimulating Household Improvements Resulting in Economic Empowerment project; detail can be seen at: http://www.shiree.org ${ }^{3}$ See the detail in the working paper-9 at shiree website (http://www.shiree.org/wp-content/uploads/2012/02/9-Accessing-andRetaining-Access-to-the-Sandbars-by-the-Extreme-Poor-Experiencesfrom-the-Practical-Action-Project.pdf)
}

3. To capture the challenges female factory workers face in trying to build their resilience

Research methodology constituted in this study has adopted four tools including (i) In-depth Interview (ii) Life History Analysis (iii) Key Informant Interviews and (iv) Secondary literature review. For the in-depth interviews, sixteen workers have been randomly selected from the eight rug factories. In the same way, for the life history analysis, five workers have been picked randomly from five rug factories. In addition to the rug factory workers, some secondary stakeholders such as the male family members of the factory workers, local leaders and factory supervisors have also been chosen for in depth interviews.

The design of the methodology adopted for this research revolves around the economic shock in 2011 when the rug factories closed for six to twelve months. The reason for this was a significant reduction in the orders made to these factories by the buyers. The study investigates the way in which this shock affected the livelihood of those women working in the rug factories and uses this shock to draw key lessons on resilience building ${ }^{4}$.

\section{Analysis and Findings}

The study finds different types of responses to the factory closure from the rug factory workers. All the households did not have equal capacity to respond to this shock as they were different in terms of their household composition, productive asset base, number of earning members in the family and social connections. The field observations show that households with more diversified income, savings and social connections could easily cope with the shock when the others with less income

\footnotetext{
${ }^{4}$ Besides, the study also covers common health-related shocks workers faced, reported by CMS $5^{4}$ data.
} 
diversification, savings and social connections found it difficult to do that.

This section deals with different coping strategies people followed during the closure, what they learned from that and demonstrated in their actions and how those actions are helping them attain resilient livelihood.

\subsection{Income Status of the Workers before and after the Involvement with Rug Factories}

Before being engaged with the rug factories, 53 per cent of the families used to depend on agri-labouring done either by both the husband and wife or husband alone and wife would work as a maid servant or work in their own home. Among the rug factory workers, 25 per cent were house wives, 19 per cent were only maid servants, 31 per cent worked as both maid servants and agri-labours and 24 per cent were in different occupations before being engaged with the rug factories. It is observed that 50 per cent of these female workers used to work as maid servants and they earned only $500^{5}$ taka in an average per month which was a relatively small contribution to the family income.

After being engaged with the rug factory, they earned 3500 taka on average as monthly income only from working in the rug factories when it is also complimented by the other incomes especially from the husbands' or from other productive assets. Again, if we have a look on the expenditure side of the households, we can see the earlier average household expenditure was just above 3000 taka when now it is more than 4900 taka. So, when the income has increased by 95 per cent, the expenditure of the rug factory workers' household has increased by 35 per cent. The remainder has been converted to savings or investment.

Among the 16 rug factory respondents, only two are female headed and managing the entire income and expenditure of the family, the remaining 14 female have their male counterparts for supporting the family. However, their average household income before being engaged with the rug factory was 2933 taka when except those two single headed families, all of them had at least two income sources implying that all the women used to work whether as maid servants or as agri-labours. But now the average household income of those families is more than 6000 taka, almost double their earlier one.

\subsection{Coping Strategy during the Closure}

As the sudden factory closure was unprecedented, the beneficiary households were not prepared for this and adopted different strategies randomly for coping with this shock. The data collected indicates that due to the lack of preparedness measures and contingency, people adopted disorganized coping strategies. Immediately after having a regular income from the rug factory, some households started repaying the previous loans and repaired the houses and 60 per cent of them had invested in some assets.

The life trajectory analysis of the rug factory workers show that during the closure, the upward wellbeing trend of the beneficiary households was stopped and three out of the five respondents, experienced a flat wellbeing trend.

\footnotetext{
${ }^{5}$ Excluding the lunch provided by the house owner
}

The rest two households suffered a simultaneous health shock showed a down trend curve.

The trajectory maps (Figure 2) of two female workers of the rug factory show three periods i.e. first phase of rug factory working, the closure period and the second phase of the rug factory workers. With the sudden closure of the rug factories, the improvement in wellbeing of the workers halted and kept stable during the period by adopting some coping strategies but the households who simultaneously faced some other shocks like health shocks could not even remain stable in their wellbeing status rather they went downward.

Among the five respondents of life history analysis, four show food coping followed by selling livestock, withdrawing saved money and returning leased land sequentially during the closure. Females with less savings and productive assets as alternative income sources were seen to even go back to their earlier occupations like agrilabouring and working as housemaids letting their wellbeing status go downward.

46 per cent of the families depended on their husbands' income during the closure. The first strategy they adopted for coping was a cut in food expenditure: the frequency of fish and meat intake of the households fell. In parallel with food coping, they also coped by selling livestock and agricultural produces, drawing down saved money and returning leased in land. In extreme cases, 24 per cent of the households needed to go back to their former profession and 18 per cent sought temporary help from relatives.

Rafeza [40], one of the rug factory workers moved to Dhaka with the aim to work for a garment factory for coping with her unemployment due to the closure. But she felt forced to return to the village and to her previous work as a day labourer.
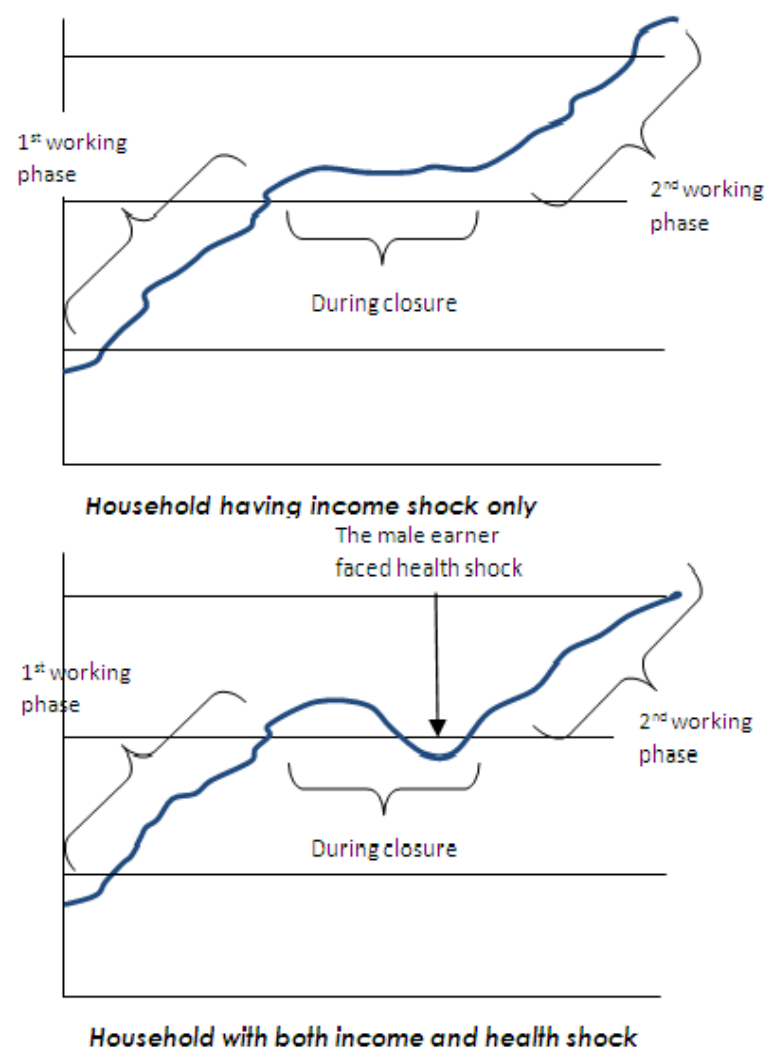

Figure 2. Trajectory maps of two BHHs in the rug factory 
Rafeza Begum [42] migrated to Dhaka for working in a garment factory during the closure but she had returned home and started working as day labourer within few months. She could not put up with the environment at the slums in Dhaka. She had to pay a high (1200 taka) house rent and as a consequence she could not afford the cost of her son's education and she felt that her son would be spoiled. In her small hut in the village, she does not need to pay any rent, she can send her son to school and there are many people i.e. neighbours and relatives to take care of them during any crisis. That is why she left the job of 4000 taka in a garment factory and resumed as day labour in her own locality.

However, this was an important learning process for them, the lessons they learned while coping with this unemployment was reflected in their behavior later on.

\subsection{Learning from the Closure and the Behavioral Changes}

The data collected shows that the experience of this closure had an impact of the financial behavior of the workers. They are now more likely to invest for productive asset creation and savings. The rug factory workers value the habits of mutual cooperation and maintaining good social relationships with the community people. More than 90 per cent of the respondents believe that they may face the similar shock again by losing their job and the savings and investment for alternative income generation they are doing are the results of that consciousness.

\subsubsection{Savings}

Although saving money is hard as it requires people to override a natural tendency to prioritize the present over the future [28], the rug factory workers are opt to savings as they have already had a shock. People also save for future as they know that after a certain time; they will not be able to do this laborious job as their physic will not permit. Workers above thirty five are very conscious that they can continue with this job for at best five years if the rug factory continues operation. So, they formulate their strategy for 'early retirement' from rug work in terms of asset creation or income diversification based upon this assumption.

Saving behavior of the rug factory workers can be clearly understood from the analysis of their Marginal Propensity to Consume (MPC). When the average MPC in Bangladesh is 0.45 , the MPC of the rug factory workers have been seen to be 0.39 . When a 100 taka increase of income leads people to spend 45 taka, the rug factory workers spend 39 taka. Many of the households have reported to have cut some expenditure especially for smoking; it has been possible for them to keep their MPC less than the average level. This lower MPC also indicates that they have more Marginal Propensity to save and to invest.

The rug factory workers have two types of savings when one is with the formal institutions and the other one is informal (cash in hand). 83 per cent of the factory workers have formal savings with banks or Micro Finance Institutions (MFIs) and the same percentage of them reported to have cash in hand always necessary to meet any sudden need. But 100 per cent of them have any of these two types of savings and 67 per cent of them have both. This saved money has been a source of confidence for them as they deliberately have done this to meet any emergency demand.

\subsubsection{Investment and Income Diversification}

As Reardon et al. [29] argues that the farm households across the developing world have been earning an increasing share of their income from non-farm sources; the rural economy of Bangladesh is also being largely dependent on the non-farm activities. The beneficiary households have diversified their income opportunities especially in the non-farm activities. The analysis shows that this diversification is the result of the deliberate effort from the rug factory workers.

This diversification is defined as push factors. To him, 'Push factors' are used as means of risk reduction and responses to diminishing returns from any given source. As after this closure, the workers have taken diversification as a means of risk reduction, this is more of a self insurance as Alderman and Paxson [30] find.

In a number of ways the households have diversified their income opportunities. The workers have been seen to have 4.4 types productive asset creation an average, which all can be considered as income source diversification. Among all these productive investments, livestock purchasing, formal or non-formal savings and land leasing have been seen more prevalent and significant to the female workers.

83 per cent of the workers have invested in livestock as it is considered to be most feasible for them to rear. When both the male and female are at work, the children can take care of the livestock and even if they are in school, they can keep the cows or goats locked in their home with sufficient food for the whole day. Investing for the livestock has been considered as the most suitable option for them as it does not need much money and time to spend when on the other hand they give a good return at certain intervals in the year.

25 per cent of the workers have been able to purchase land whether for cultivation or for dwelling when 42 per cent of them have taken land with lease but 53 per cent of them have taken land with any of these systems. Among other investment areas, 50 per cent of the workers are investing for their children's education and 25 per cent of them are investing for cultivation.

However, 16 per cent of the households have been seen in investing highest 6 types of productive asset creation or income diversification at a time when 35 per cent of them in investing for 5 types and 25 per cent in both for three and four types. So, the rug workers have invested for highest 6 types and lowest 3 types of productive asset creation or income diversification. And as all the households have, except two, working husband, they have one more income opportunities each.

\subsubsection{Increased Level of Social Connectedness}

Maintaining a good relationship and mutual understanding among the fellow workers is a conscious effort from the rug factory workers as they know that they not only belong to the same class, but also can be the most available and nearest source of getting support. They also feel that they might need some support from the landlords as some of them need to go for agricultural laboring 
during the closure period and they now feel that if there is a crisis for a longer time, and they cannot tackle that with the savings and the assets they have accumulated so far, they might need to go laboring again and that is why, maintaining a relationship or communication with the land owners and the laboring groups is also essential for them. These actions have also helped them remain cohesive in the society.

In the rug factories, enabling working environment has been promoted with the mutual understanding and cooperation by all the workers. The fellow feeling arose as they feel that they have come from the same group or status. This sense of fellow feeling makes them extend their cooperation to each other in the time of sudden distress. The workers lend money to each other if anyone of them needs that. They have been found to collect subscription for supporting treatment of fellow workers.

The CMS 5 data show that due to the community solidarity building approach, Abida, ${ }^{6}$ one extreme poor beneficiary was supported by the community people with almost 6000 taka for repairing the house torn with the cyclone. The community people collected subscriptions from every household at the community and as being deserted by the husband she had none to manage the repairing work, the community people led by the PUC, managed to repair the house. For the rug factory workers, this sort of cooperation is more promising as they have established some certain examples of mutual cooperation among themselves.

The rug factory workers have been found helping each other during the health shock and arrangement of marriage ceremony of their daughters by providing some cash. Sabina, one of the rug factory workers noted, 'we all poor people are working here and staying like a family. That is why we need to stand by ourselves; today someone has some crisis but it may also be that I will be in the same situation in near future'. This is how she clarified why they remain connected and cooperative to each other.

\subsection{Impact of Diversification and Social Connectedness on Livelihood Resilience}

Income diversification and social connectedness can play a significant role in attaining resilient livelihood. The data collected shows that the rug factory workers know well that the savings, productive asset and their social relations will be potential means of coping with future income shocks and that is why, they are more sincere of maintaining these.

The data shows that the rug workers earlier were hardly assisted by the relatives, neighbours and by the MFIs earlier but now they can enjoy three tiers of financial supports from the fellow workers, the relatives or community people and the MFIs. They have reported to meet any sudden demand of less than 5000 taka with the assistance of the co-workers, and for larger amount, they can go to the relatives and finally to the MFIs.

Increased level of economic capacity also helps people access supports from the socially connected people like the community people, relatives and friends and also from the MFIs. People invest in social relationships with the

\footnotetext{
${ }^{6}$ A CMS 5 beneficiary; detail can be found at shiree website: http://www.shiree.org/extreme-poverty-monitor/cms-5-trackingstudies/\#.UonZVCcm108
}

expectation of some return [31] and that is why individual earning capability has a strong impact on whether he or she will be assisted by others. During the in depth interview, Laila ${ }^{7}$ noted that few days ago she took loan of 30,000 taka from her uncle in law. She also reported that whenever she needs money, she just calls him without hesitation and he also lends the money confidently. She recollected that before attaining this social and economic status, it was quite impossible for her to receive this sort of support from him or from any other relative.

The rug workers reported that, during the sudden financial need, they can go to the MFIs for borrowing money where they are depositing that regularly. 83 per cent of the workers are involved with any of the MFIs for saving money and they all are eligible to take some loans from those MFIs.

Apart from these, the rug factory workers are well aware of their possible opportunity to work with the embroidery and stitch craft if there is any sudden closure of the rug factory. There are some small entrepreneurs at the rural areas and they have certain demand for workers as well. The skill they have acquired through the training and through their work can be utilized in some other ways as well.

However, the study has found that the assurance of regular income from the job at rug factory has also helped the workers purchase the daily consumption items from the grocers' shop at the communities with credit. The workers reported that in several months they needed to go for buying food and some other cooking ingredients with credits from the local grocers' shop as at the end of the months they ran out of money. The shop owners did not hesitate to sell those with credit mainly because of two reasons: they had the ability to repay the loan in due time from their regular earning and they had more social value and acceptance among the community people.

The rug factory workers have also been able to establish a good connection based on social fellowfeelings and respect through the community solidarity building approach of CARE. Through intensive field facilitations, consultations and group discussions by the field staffs at the community level, the extreme poor people have got some social connectedness by which they can be assisted by even the community people in the time of distress. The case of Abida shows how the community people became proactive in helping her repair the damaged house.

In line with the conceptual framework, the rug factory workers are more likely to cope with income shocks by forgoing the productive assets they have accumulated from the increased level of income and at the same time, they are found to maintain a good social connection-which all can be considered as potential source of support while coping with income shock and thus these can help them attain resilient livelihood, though there are some challenges remaining.

\subsection{Challenges of Building Livelihood Resilience}

Although the proliferation and collaboration of the private sectors with the NGOs is not new in Bangladesh,

\footnotetext{
${ }^{7}$ A rug factory worker
} 
the modality of this collaboration has not yet got formalization and so has some challenges. Availability of the cheap labor among the extreme poor people has made the private sector more interested to come to a collaborative approach where the NGOs will ensure, in most of the cases, the initial labor section for recruitment and primary level capacity building so that the extreme poor people can be engaged with the production. But it has been observed that after a certain time, the NGOs withdraw them from the scene and often have a limited follow up and monitoring. Although, for CARE, the staffs remain in touch of the factories and the workers, the rug factories are not an issue to be frequently monitored and that is why, there are some challenges remaining in the entire system that have some potential to hamper the path towards resilient livelihood for the workers.

Late payment and static wage rate are the two major problems the workers face while working in the rug factories. The workers are paid after fifteenth of every following month instead of the first week though the due time payment would help them deposit the installments for the different deposit skims they have with formal and non-formal institutions. They also reported that they were having the same rate of payment from the last two years though they had had the inflationary pressure on the prices of their consumption goods.

Working in the rug factory is a laborious job and it often initiates back pain and chest pain of the workers. Apart from the normal life stressors, the physical pressure a person experiences in the workplace can independently increase their health risk. That is why, continuing this work for several years at random is quite difficult. The workers have reported to take medicine regularly for recovering the chest pain and back pain though they are not provided with any medical allowances.

Eventually, late supply of the raw materials has often been reported by the rug workers, which incurs a huge loss for the workers. In an average a rug factory worker can produce 14 pieces of medium size rug in a day but when there is shortage of the raw materials, they need to halt their production and thus incur a loss in their daily income.

In addition to these, a good physical working environment has also been demanded by the workers. The reported, the factories lack sufficient light and air flow, which hampers their work. The rug factories have not been provided with electrical lights or fans and that is why often the factories become dusky and frowsy, which they feel as obstacles to their work.

\section{Conclusion and Implication for Strategy}

Increased level of income has eventually driven the rug factory workers to go for asset creation and income diversification. For many of the rug workers' family, the involvement of the female with this regular income scope has itself become the income diversification as they had the male earning members but some of them had no such bread earner those female used to work by themselves as day laborers or as domestic labors for earning their living. So, this engagement with the private sector by CARE Bangladesh has been meaningful for the families as they have got either income generation or income diversification; but in any way, it has contributed to have some more money to the families, which have led them to have some more asset and deliberate income diversification.

However, some households did suffer from insufficient resilience. Those who suffered the most were single earners and those who faced double shocks during the closure (especially those who incurred health shocks affecting the other breadwinner and medical costs). Those who were not able to build up savings and diversified investments in the period prior to the factory closure also suffered, for instance those moving up to level 48 were far more likely to sustain resilience than those who have not.

The sudden closure of the rug factories has also brought some lessons for the worker and they are now more conscious of having some preemptive measures for coping with the potential shocks. They are now trying to invest more for diversifying the assets so that they can utilize them during the crisis. They consider their working in the rug factory as an opportunity, which is uncertain in terms of it continuation and that is why, they are trying to make the most out of it so that in the long run they can live on the other income scopes if there is no working opportunity in the rug factory.

Apart from individual efforts for having more resilience, the promotion of social solidarity among the rug workers and their linkages with the surrounding people like the relatives, neighbours and the community members have also created some scopes for them to be in a better position in a critical situation. Due to the greater level of social connectivity, the rug factory workers are now having three tiers of financial protection from the fellow workers, community people and relatives and also from the MFIs.

In fine, it can be said that engagement of the extreme poor households with private sector for their employment can be effective for resilience of their livelihoods but wages and necessary health and safety measures are to be fairly ensured. A decent working environment is a precondition for promoting livelihood resilience for the rug factory workers. SETU project of CARE Bangladesh targeted adult females, so the income would create the resilient livelihood options for the households by having at least two income sources. It also moves woman from lower productivity housemaid work to higher productivity rug factory working where they are considered as 'employees' not labours or housemaids, which is an evident recovery from the social stigma of the workers. As the rug making is considered 'high status' work and at the same time give some regular good amount, men are more supportive to the women who would otherwise work only in their home or as housemaids or in the agricultural fields as agri-labours.

Based on the analysis given above, several recommendations can be drawn in:

A proper operational manual or Standard Operating Procedure (SOP) for the rug factories needs to be in place so that the rights of the workers are ensured in a more formalized way. That manual will ensure a good and healthy working environment at the factories when it will also state the strict guideline for the salary payment,

\footnotetext{
${ }^{8}$ Non-poor status in the trajectory map
} 
increment, medical allowance and other facilities for the workers. At the same time, the manual will ensure the discipline and working modalities for the workers. Although CARE has taken a proactive role here in negotiating with the Classical Handmade Products-BD, both the parties can have a joint initiative to develop and agree upon the operation manual and the Terms \& Conditions in it. This manual will ensure the win-win situation of both the private company and the workers by ensuring benefits for both of the parties, which will eventually help them have more sustainable livelihoods.

Though the rug factory workers have diversified their income normatively and also deliberately, a necessity of awareness raising among the workers was felt during the interviews. Frequent follow-up visit with facilitation of analysis for appropriate decisions about their individual move-on strategies might be helpful for resilience of their livelihoods. For an example, Jaheda, a rug factory having no working member in the family leased in some land and had become dependent on the hired labours which was not eventually cost effective for her. In this case, she could have adopted any other means that would be economically viable for her and also manageable for her when Nasima, another woman was seen to be unknown how to access the medical treatment of the goats she was rearing. So, in these cases, some more guidance and assistance from the NGOs is needed so the diversification initiatives can be more helpful for the workers.

\section{Acknowledgement}

The Author conducted this research when he was working with CARE Bangladesh. This research was funded by SHIREE.

\section{References}

[1] Household, Income, and Expenditure Survey, (2010). Dhaka: BBS.

[2] UNDP, (2013). Eradicate extreme hunger and poverty. http://www.bd.undp.org/content/bangladesh/en/home/mdgovervie w/overview/mdg1 Accessed on 10 November, 2013

[3] Rahman, M. Mizanur, (2013). Making agriculture commercially viable to the poor, The New Age http://www.newagebd.com/detail.php?date=2013-04$17 \&$ nid $=46257$

[4] Lanjouw, P. \& Stern, N. 1993. Markets, opportunities and changes in inequality in Palanpur, 1957-1984. In A. Braverman, K. Hoff \& J. Stigliz, eds., The economics of rural organization: theory, practice and policy. New York, USA, OUP.

[5] Estudillo, J. P., \& Otsuka, K. (1999). Green Revolution, Human Capital, and Off-Farm Employment: Changing Sources of Income among Farm Households in Central Luzon, 1966-1994. Economic Development and Cultural Change, 47 (3), 497-523.

[6] Momen, N. Md. (2007). Implementation of Privatization Policy: Lessons from Bangladesh. The Innovation Journal: The Public Sector Innovation Journal, Volume: 12 (2), Article: 4.

[7] Hossain, M. (2004). Rural non-farm economy in Bangladesh: A view from household surveys (No. 40). Centre for Policy Dialogue (CPD).

[8] Mahmud R.B (2012) Skills development in Bangladesh RMG sector, the News Today: http://www.newstoday.com.bd
[9] IFAD, (2012), Deepening IFAD’s engagement with the private sector

[10] Sobhan, R. (1998). How bad governance impedes poverty alleviation in Bangladesh. OECD.

[11] Barrett, C. B., Reardon, T., \& Webb, P. (2001). Nonfarm income diversification and household livelihood strategies in rural Africa: concepts, dynamics, and policy implications. Food policy, 26 (4), 315-331.

[12] Alderman, H. and C.H. Paxson. (1992). "Do the Poor Insure? A Synthesis of the Literature on Risk and Consumption in Developing Countries,” World Bank Policy Research Working Paper WPS 1008.

[13] Reardon, T., Taylor, J. E., Stamoulis, K., Lanjouw, P., \& Balisacan, A. (2000). Effects of non-farm employment on rural income inequality in developing countries: an investment perspective. Journal of Agricultural Economics, 51 (2), 266-288.

[14] Barrett, C. B., Reardon, T., \& Webb, P. (2001). Nonfarm income diversification and household livelihood strategies in rural Africa: concepts, dynamics, and policy implications. Food policy, 26 (4), 315-331.

[15] Omamo, S. W. (1998). Farm to market transaction costs and specialisation in small-scale agriculture: Explorations with a nonseparable household model. The Journal of Development Studies, 35 (2), 152-163.

[16] Reardon, T., Delgado, C., \& Matlon, P. (1992). Determinants and effects of income diversification amongst farm households in Burkina Faso. The Journal of Development Studies, 28 (2), 264296.

[17] Barrett, C. B., Reardon, T., \& Webb, P. (2001). Nonfarm income diversification and household livelihood strategies in rural Africa: concepts, dynamics, and policy implications. Food policy, 26 (4), 315-331.

[18] Stuart, R. (2000). The poor and their money. January 2000.

[19] Duflo, E. (2007). The economic lives of the poor. The journal of economic perspectives: a journal of the American Economic Association, 21 (1), 141.

[20] Chambers, R., Conway, G., (1992). Sustainable rural livelihoods: practical concepts for the 21st Century. Discussion Paper 296. IDS Sussex.

[21] Weick, K.E; Sutcliffe K.M; and Obstfeld, D (1999) Organizing for High Reliability. Research in Organisational Behaviour 21 81-123

[22] Sutcliffe, K.M and Vogus, T (2003) Organising for resilience, in, K.S. Cameron; J.E Dutton; \& R.E Quinn, eds., Positive Organisational Scholarship: Foundations of a new discipline 94110, San Francisco, Berrett-Koehler.

[23] Kabeer, N. (2012). Women's economic empowerment and inclusive growth: labour markets and enterprise development. SIG Working Paper.

[24] Mondal, A. H. (2000). Social capital formation: The role of NGO rural development programs in Bangladesh. Policy Sciences, 33 (3-4), 459-475.

[25] Chambers, R., Conway, G., (1992). Sustainable rural livelihoods: practical concepts for the 21st Century. Discussion Paper 296. IDS Sussex.

[26] Carter, M. (1997). 'Environment, Technology, and the Social Articulation of Risk in West African Agriculture', Economic Development and Cultural Change, 45 (3): 557-591.

[27] Ellis, F. (2000). Rural livelihoods and diversity in developing countries. Oxford University Press.

[28] Karlan, D. (2010). Helping the Poor Save More. Stanford Social Innovation Review, 48-53.

[29] Reardon, T., Berdegué, J., Barrett, C. B., \& Stamoulis, K. (2007). Household income diversification into rural nonfarm activities. Transforming the rural nonfarm economy: opportunities and threats in the developing world, 141-82.

[30] Alderman, H. and C.H. Paxson. (1992). "Do the Poor Insure? A Synthesis of the Literature on Risk and Consumption in Developing Countries,” World Bank Policy Research Working Paper WPS 1008.

[31] Brisson, D. S., \& Usher, C. L. (2005). Bonding Social Capital in Low - Income Neighborhoods. Family Relations, 54 (5), 644-653. 